\title{
THE SENSE OF PLACE IN COMMUNITY PARTICIPATION THROUGH TACTICAL URBANISM IN BUNDARAN HI, JAKARTA
}

\author{
Salsabila Andara Siskania Alyani ${ }^{1}$, Herlily $^{1 *}$ \\ ${ }^{1}$ Department of Architecture, Faculty of Engineering, Universitas Indonesia, Depok 16424, \\ Indonesia
}

(Received: August 2018 / Revised: August 2018 / Accepted: January 2019)

\begin{abstract}
The sense of place is a concept within urban design. In the realm of formal city planning, sense of place is likely correlated with the physical feature of a city. However, academic studies show that sense of place is multidimensional, which involves factors that is beyond mere physical attributes. On the other hand, tactical urbanism as an emerging concept which describes an intervention that is implemented in a city is conceived as a public's opportunistic response to formal spatial planning. Being associated as interventions throughout the city, one of tactical urbanism's main character is its bottom-up nature which responds to specific issues that lie behind the movement. Moreover, tactical urbanism focuses on action. In Indonesia, negotiation of micro-scale spaces such as a pedestrian, street corners, and hawker spaces can be considered as tactical urbanism action, as it defines the character of an area which eventually generates a certain sense of place. The focus of this study is to investigate the creation of a sense of place within a public realm that undergoes tactical urbanism initiation by interrogating whether the factors of tactical urbanism contribute to the enhancement of a particular area's sense of place. We will use the emic approach to understand the tactical urbanism adaptation. The analysis will show how specific adaptation of tactical urbanism is implemented in the given case study. By examining the tactical urbanism process, this paper shows the role of actors and their contribution to the creation of a sense of place.
\end{abstract}

Keywords: Community participation; Sense of place; Tactical urbanism; Urban; Urban planning

\section{INTRODUCTION}

Cities have collections of phenomena in its everyday life. As cities have been built as rigid formal spatial planning, actions of people stand within its public realm as responses to their surroundings. This form of adaptation is found on the public realm in Jakarta alone in various scales of spaces and action. With its complicated everyday life, Jakarta's street corner hawkers spaces, sidewalk life, and so on; have contributed micro-scale actions that create a certain sense of place of an area.

In the other side, the term tactical urbanism emerged as a bottom-up, low cost, and practical solution to formal spatial planning issues (Lydon et al., 2015). To that end, tactical urbanism appeared as interventions that focus on the actions of communities, relating to its bottom-up nature. The formal physical spatial arrangement of both places has impacts on people's perspectives that trigger spontaneous actions towards their environment.

*Corresponding author's email: herlily@gmail.com 
Throughout the paper, we explore a phenomenon at one of Jakarta's public space as an approach to tactical urbanism and subsequently examine the creation of a sense of place in the area. Given the small-scale idea of tactical urbanism, community-focused actions have occurred to be one of the essential character of tactical urbanism. Thus, this paper examines ways in which tactical urbanism happen in a more informal setting and how the action is enforced by the participation of local citizen. This discussion of a sense of place and tactical urbanism will talk about the context from which a phenomenon inside the community emerged, how the whole tactical urbanism project took place, and the subsequent creation of a sense of place. This paper uses the emic approach as the method to understand the spatial practice of visitors in Bundaran HI and survey method through semi-structured interview and questionnaires. The descriptive methods used are journals and books. Meanwhile, the scope of this writing is the subject limited to the visitors inside the Bundaran HI area in Central Jakarta only.

\section{LITERATURE REVIEW}

In order to comprehend the correlation of sense of place and tactical urbanism concepts, several elements involved in the creation of each component were defined, both from the sense of place and tactical urbanism. These elements will then become the benchmark in observing the creation of a sense of place from the perspective of tactical urbanism.

The concept of sense of place has always been discussed as one of the major issues in environmental psychology and architecture (Beidler \& Morrison, 2015). The sense of place is derived from the concept spirit of a place or genius loci (Jackson, 1994). According to Jackson (1994), when occupying a place, a man can have experiences beyond physical and sensual experience, which is feeling a certain attachment to a place and the elements within that is referred to the spirit of the place. For Tuan (1977), a place without any hint of man in it is just a small geographic location. Thus, the meaning of place is closely related to the feeling of secure and attached, as opposed to the meaning of space (Tuan, 1977).

When occupying a place, a person goes through a process of perception towards its environment. According to Steele (1981), perception is the process in which a man receives information from its surroundings, and thereupon immediately gives meanings based on the given information. In perceiving a place, Carmona et al. (2003) explain that sensation plays a big part initiating the process of perception. The author continues that sensation is the result of collection from the four senses: sight, hearing, smell, and touch.

In the relationship between human and place, a setting is one essential component (Steele, 1981). According to Steele (1981), the setting is a man's surroundings in a specific time and location, which consists of physical and social factors. In this regard, Najafi \& Shariff (2011) explains that both social and physical factors are interactional and affect each other. According to Shamai (1991), who conducted a study about the measurement of the sense of place, there are three phases of the sense of place. The first is the ownership of a place, the second is the attachment to a place, and the last one is the commitment to a place (Shamai, 1991).

The aforementioned physical factors are geographic location, scale and proportion, geographic distinctiveness, and rich imagery (Steele, 1981). Regarding rich imagery, Lynch (1960)'s concept of imageability that consists of the path, node, district, edge, and landmark as elements in the city contributes to a place's distinctiveness and imagery.

Besides physical factors, Steele (1981) explains several social factors that contribute to the spirit of a place. Those factors are effects on numbers of people, social climate, and characteristics of the people. Steele continues that a place can generate a massively different 
spirit of place with numbers of people inhabiting a place, to illustrate, a jam-packed football stadium has an entirely different spirit than when it is empty.

In the past few years, the concept of "tactical" urbanism has emerged as a brand of small scale intervention (Talen, 2015). Lydon et al. (2015) explain that if the world tactical is associated with a city, tactical urbanism is an approach to develop potentials of a neighborhood through low-cost, short-term, and flexible interventions. Therefore, tactical urbanism is an intervention which occurs in the city and has specific goals for its underlying issues.

Tactical urbanism is a term that explains a various form of interventions in a city (Silva, 2016). According to Silva (2016), tactical urbanism is a product of complexity that goes on within the urban realm. The complexity is seen as a system that affects each other so that every element involved is inseparable (Batty, 2007 cited in Silva, 2016). For that matter, each events happening inside a city is seen as a complexity, whether it is micro or macro-scale.

Silva (2016) mentioned several characteristics of the conducted tactical urbanism initiatives. Tactical urbanism does not have to involve every following characteristic, but at least it must have one of them. First, "specializing" means goal identification from clear and specific intervention in responding toward an issue. The second is "following up." Silva mentioned that every precedent intervention had become an inspiration for the tactical urbanism actor. The third is "adding." The adding of an element within an established environment is one of the tactical urbanism characters. The element adding will then refer to the function adding that happens in the environment. The next is "settling." Short-term intervention better has long-term impacts that respond to formal policy. The fifth is "claiming." It expresses a community's needs. The sixth is "monitoring." Several tactical urbanism interventions are monitored by formal parties as a policy trial before being implemented. The last is "merging." Tactical urbanism can be conducted by involving more than one actor. One of the examples is the involvement of local actor that is supported by the role of the non-profit organization.

The bottom-up character in tactical urbanism appears as a response to a city's character which is to undergo adaptation (Silva, 2016). Weinstock (2013, cited in Silva, 2016) explains that a city will adapt to its limits. To conclude, Silva (2016) states that adaptation occurs as a possibility to change functions inside a city without changing its physical context.

According to Lydon et al. (2015), there are three applications of tactical urbanism. First, tactical urbanism is initiated by the public as progress to deliver their aspiration. Second, tactical urbanism is initiated by the government, developers, or non-profit organizations to involve public on any project planning. Lastly, tactical urbanism can be used as an instrument to test out a project before the long-term investment is set.

One of tactical urbanism's character is to transform a place that is residual or owning characters of looking less alive (Lydon et al., 2015). With the existence of tactical urbanism intervention, it is expected that the action will increase the publicness in previously dead public space (Spataro, 2015). Public spaces in Asia is further discussed by Hou (2010) and mentions a few characteristics in Asian public spaces that are insurgent and spontaneous. According to Hou (2010), public spaces in Asia play their roles to assist the public to undergo social interaction and deliver political expressions, not just limited to the aesthetic of its physical elements (Hou, 2010).

People tend to stay in a place where there are other people in it (Lydon et al., 2015). In doing activities in public spaces, Gehl (2011) mentions three categories of outdoor activities. First, necessary activities are primary activities that occur on a daily basis. Second, optional activities are recreational activities and tend to be more of choice in daily life. Lastly, social activities are resultant between both activities because of the social interactions, whether they are actively or passively done. 
In the phenomenon of tactical urbanism, the movement has underlying issues behind it (Lydon et al., 2015). Factors that play significant roles in the process are the actors, the location, and the actions. In this regard, tactical urbanism contributes to the making of a sense of place by the alteration done by the people. Moreover, the previously mentioned physical and social factors of a place act as the spirit of place that triggers potential options of actions toward the actors' neighborhood, which subsequently shows as a tactical urbanism action.

\section{RESULTS AND DISCUSSION}

\subsection{Tactical Urbanism in Bundaran HI}

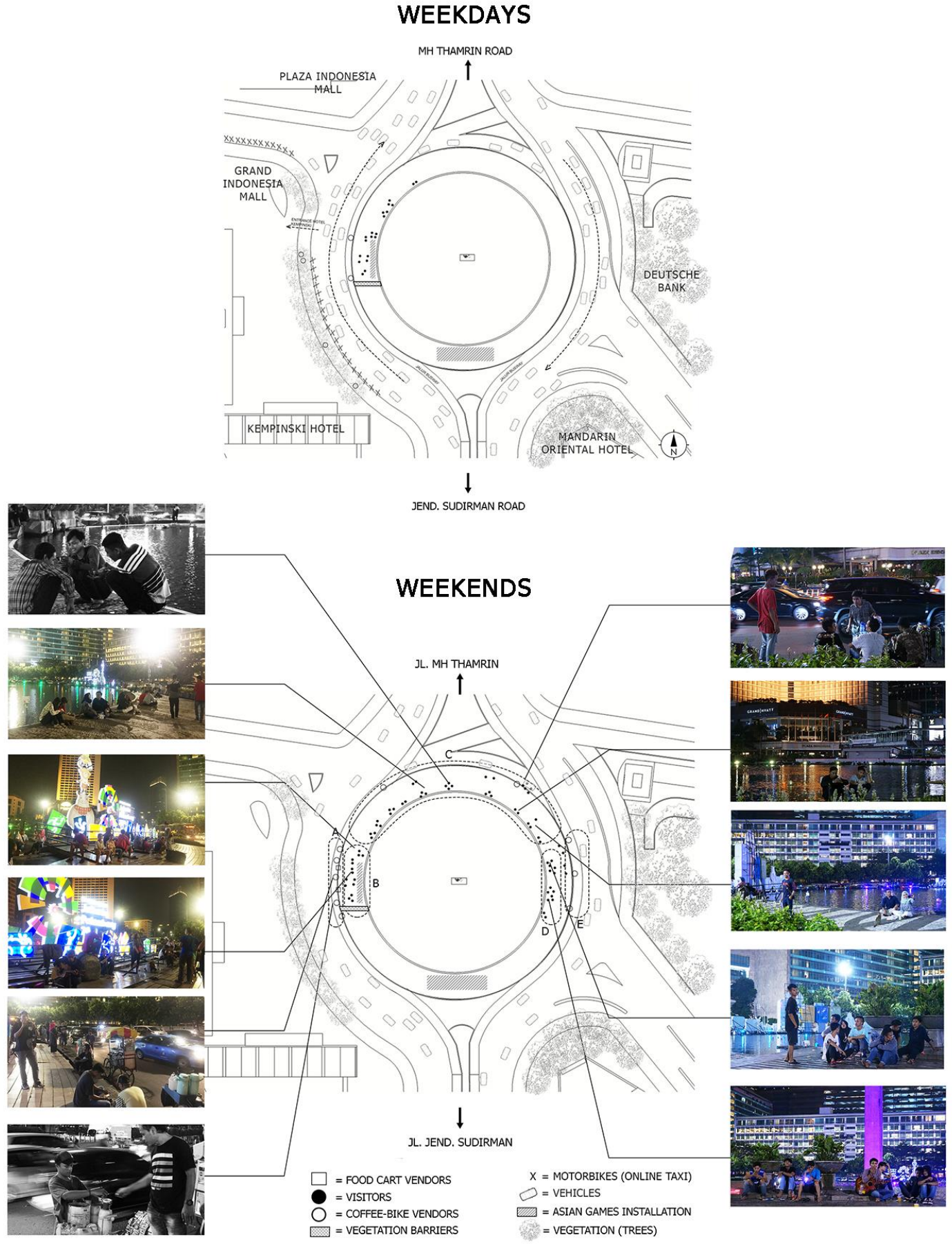

Figure 1 Mapping of activities at bundaran HI on weekdays and weekends Source: Benhur N. (2014). www.3dwarehouse.sketchup.com with alteration 
Bundaran Hotel Indonesia (Bundaran HI) is the intersections of four renowned roads in Jakarta: M.H. Thamrin road, Jenderal Sudirman road, Sutan Syahrir road, and Kebon Kacang Raya road. Bundaran HI is recognized as the capital's center, from which the high intensity of activities occurs every day, during the day and night. The high level of activities is contributed by the existence of the buildings surrounding the roundabout, which consist of two famous malls: Grand Indonesia and Plaza Indonesia, hotels: Grand Hyatt, Kempinski, and Mandarin Oriental, and also lines of other skyscrapers that function as office and other commercial needs.

Lim (2008) explains that the changes have been done at Bundaran HI and the relation between the actions of people that can lead to political actions. In 2003, Bundaran HI underwent renovation, and one of the most preeminent change is the renovation of the walking surface. According to Lim (2008), the changes from a flat surface to a slanted surface will eventually prevent more insurgent political actions that concern the state, such as the civic's political actions during 1998. Thus, by enhancing aesthetic aspects of the roundabout and using a renovation as a pretext, the government has taken infrastructure matters as ostensible reasoning to avoid future unwanted public actions.

During the evening, it turns out that there is a phenomenon which involve the insurgent appearance of the public in Bundaran HI. Especially during the weekends, there is a presence of public that stays and sits for hours inside Bundaran HI. Based on the observation, during the weekends this phenomenon starts at around 19.30. People walk from across the roundabout, mostly crossing from Hotel Kempinski and just beside the police station in the east. Most of the people chose to cross from the Hotel Kempinski pedestrian. This can be caused by the presence of two malls, Grand Indonesia and Hotel Indonesia in the west and northwest of the roundabout, in which the area surrounding the two malls are more densely populated than the other perimeters; where there are lines of online ojek, passerby, and people sitting on the bench.

At 21.00, Bundaran HI has already been jam-packed with visitors that linger along the roundabout. People linger and sit on the slanted surface on the roundabout. Various activities make the public space more alive. With the approaching Asian Games 2018 installation and Selamat Datang Monument in the roundabout, both objects seem to be the main point of interest and feature, besides the scenery of the city itself. With the rambling photo-taking activities, the public willingly took photos mainly with the Asian Games installation and the monument. They did take the photos both in groups and individually. The people mainly use their phones to take photos. Despite the actions of sitting from the outside, there are reasons for the public's visits to Bundaran HI. Relating to Lynch's imageability, the roundabout's preceding reputation and role as both landmark and node has become one of the main reasons of people's visits.

At point B, there are more children present with adults' company. There are young adults playing guitar and singing with their groups. Moreover, there is transaction going on between the public and coffee-bike hawkers. In this transaction, the seller approaches the groups to offer their drinks, although most visitors come over to the bike and pay, which then the seller delivers the coffee to the groups.

While sitting and lingering, the sounds of chatters are impossible to be absent. People travel in groups: the highest amount of group is groups of 3, followed by groups of 2, and there is barely anyone who travels individually to this roundabout. People in groups sit in circles or in a linear position facing the outward of the roundabout, which is the scenery of the city. In this activity, people talk without actually facing each other and conversation seem to vary from the lively to more serious conversation, indicated with the existence of laughter in each conversation. Besides chatting, most of the visitors also smoke, especially male visitors.

During the weekdays, the intensity of people is way lower than the weekends. During the weekends, visitors start to come only at 20.00 to 21.00 , after the numbering traffic system end. 
One of the hawkers also stated that after the numbering system end, they could more loosely travel to the center of the roundabout without having to worry about getting evicted by officials.

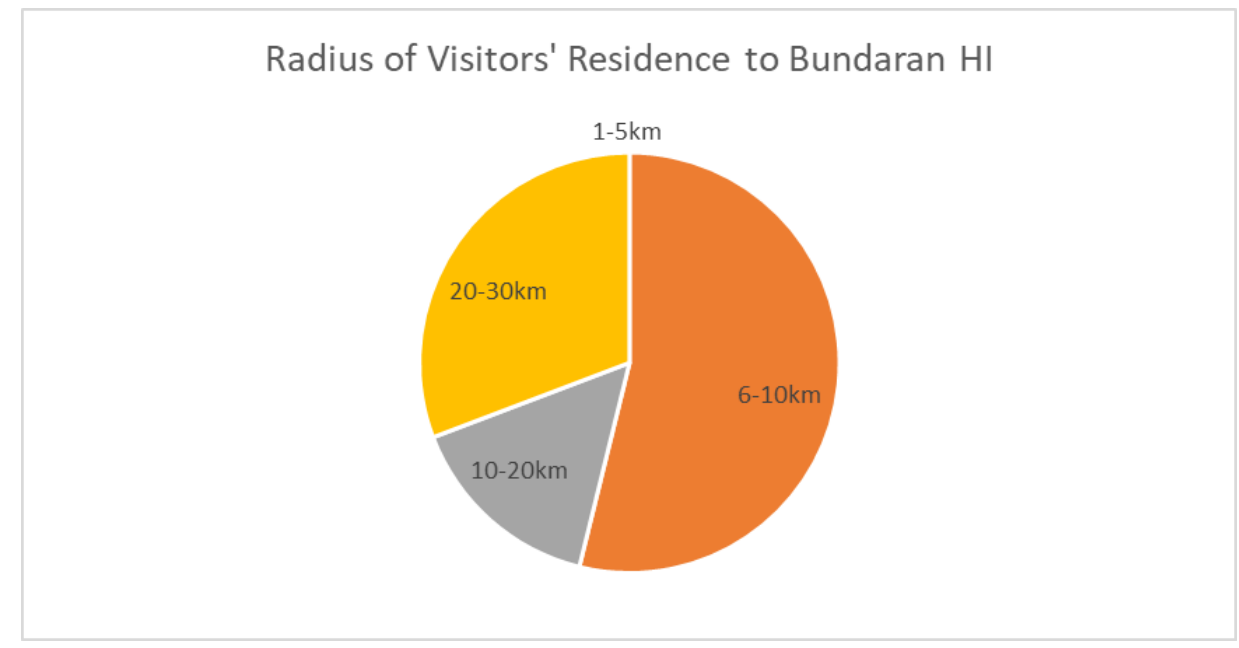

Figure 2 Radius of People's Residence to Bundaran HI

Relating to openings and visual access, Bundaran HI has open access towards itself. Two openings are available on the west and the east side of the roundabout, since the rest of the roundabout is covered with 2-meter-wide vegetations, which makes it impossible for people to cross through it. From this phenomenon, we can see that the surge appearance of the public during the night has countered the 2003 renovation project pretext. The intervention was done in a specific range of time, with recreational purposes as their initial reasoning behind the phenomenon.

Based on the above data, most of Bundaran HI visitors reside fairly far from Bundaran HI. On the other hand, the scope of activities in the roundabout is recreational such as sitting, peoplewatching, taking photos, and any other group-based activities. The scope of activities shows that Bundaran HI initially has already been a particular interest with its past reputation as nodes and landmark; whether it is because of the existence of the Selamat Datang Monument or the views of the cityscape of Jakarta from inside the roundabout.

Based on the surveys, the visitor comes to Bundaran HI to mainly sit around with their groups and relax. 10 out of 10 visitors that have been surveyed are on the productive age (ranging from 15 to 64 years old). The combination of the choice of time and age range relates to the fact that the roundabout is used as space for optional activities that are done by actors of productive age. People who visited Bundaran HI after working hours show that their common motivation and background play a prominent role in the creation of a sense of place which will then increase to people crowd in this area.

Bundaran HI is inseparable with the street vendors. One of the most dominant existences is coffee-bike vendors. The coffee-bike vendors mostly roam around the circle, mostly on the west and east side if the Bundaran HI, adjusting with the openings of the roundabout. Every day, the vendors sell their products from $8 \mathrm{pm}$ until $4 \mathrm{am}$. In this case, the vendors' water stock will run out during that period. If the stock runs out, they go to Jalan Teluk Belung to refill the hot water and ice cubes. According to a seller, the shop that is located around Jalan Teluk Betung is the shop that they most frequently visit.

The bottom-up intervention comes alive with the presence of optional activities happening inside the roundabout. Sitting around, chatting, drinking coffee, playing guitar, are forms of interaction that release work stresses, even more with the cityscape at every degree possible 
outside the roundabout. On the other hand, we can see the dominance of social activities actively occur in between every chatters and transaction between the visitors and the hawker.

The bottom-up intervention with the people who do optional activities shows that Bundaran HI has become a public space that supports the occurrence of deep interaction, as mentioned by Gehl (2011). The success of tactical action in vitalizing Bundaran HI is shown by the running of social activities that are active with the conversation of each visitor groups or through transactions between the visitors with the vendors.

Seen from the time and actor dimensions, in the sustainability of intervention in Bundaran HI, the visitors first come to the area. After there are sings of crowds in the area, about thirty minutes after, the coffee vendors go around the area to sell their coffee. This shows that the intervention tactic is initiated by the people as the visitor and leading actor, while the vendors act as a complementary element in the intervention process by influencing the visitors' duration to stay in the area with their assets.

\subsection{The Sense of Place in Bundaran HI}

With the existence of skyscrapers and shopping centers on the west side, the night lightings have become the roundabout's supportive physical element in its spirit of a place. From this sensory experience, the spirit of place created by the physical element is produced by the all Bundaran area as a holistic entity. The imageability of Bundaran HI as the node is shown through the function of Bundaran $\mathrm{HI}$ as the vehicle intersection point that has six turns. Besides, it can also be defined from the existence of two landmarks inside the Bundaran HI, which are Monumen Selamat Datang dan the Asian Games Installation.

The doers and watchers in this phenomenon can also be defined by the people from the inside and outside the Bundaran HI perimeter. Before the area was crowded, the vehicle occupants that pass by the roundabout acted as watchers without any specific doers as the object in the roundabout. However, after the intervention by the visitors occurred, it is safe to assume that the visitors who stay in Bundaran HI acted as the principal doers, and the vehicle occupants around the Bundaran acted as the watchers.

In this phenomenon, the cognitive background and perception of each actor become the factor that creates the sense of place for the user. In this phenomenon, the existence of the coffee-bike vendors contributes to a different creation of a sense of place in the roundabout. The motivation and background of the experience of the vendors also contributed further to the visitors who inhabited the Bundaran HI with their marketing activities, which affected the duration of visitors in inhabiting the roundabout.

In a phenomenon of tactical urbanism, there are issues behind any movements and intervention (Lydon et al., 2015). Place or setting as an urban tactical movement has physical and social factors that will ultimately create a sense of place. From the analysis, physical and social factors will then affect the creation of tactical urbanism seen from the factor of location, intervention type, actor, and time with the creation of a sense of place after the intervention occurs.

In Bundaran HI, the tactical urbanism is supported by the role of Bundaran HI as a node and Monumen Selamat Datang as the landmark of Jakarta. Visitors had already known Bundaran Hi with their perceptions, based on its reputation. Furthermore, space is not designed and made for people to stay there. However, based on the space-for-people issue, the visitors of Bundaran HI do intervention tactic by coming to Bundaran as their spot, which is then supported by the presence of vendors as their market source.

Seen from the place identity, the creating factor of a sense of place includes physical setting, activities, and the place meaning. In Bundaran HI, the identity is sharply defined from the past 
reputation of Monumen Selamat Datang and the location of the Bundaran HI itself, which is the center of the capital city. Moreover, the crowded condition surrounding the perimeter of the roundabout originating from the buildings around it was seen as a potential geographic location for the intervention by the visitors in which the surveillance is high enough to spend their evenings.

The spontaneous action of the people is a character that describes the opportunistic nature of tactical urbanism, as mentioned by Lydon et al. (2015). As explained by Silva (2016), tactical urbanism action in Bundaran expresses adding and claiming characters because of the shift in function and alteration, which is the presence of people. However, other than the existing characters, there are differences between tactical urbanism in Indonesia and precedent tactical urbanism, that is caused by different culture. The Jakartan's spontaneous tactical character refers to each of the actors' needs, for recreation and small-scale business. The findings are that people come to Bundaran HI to fulfill their social interaction in the middle of the city, and that is a form of response to formal planning in Jakarta. Thus, the act of tactical urbanism in Bundaran HI, Jakarta is marked by the alteration of initial function and the increase of some people as a form of intervention.

\subsection{The Creation of Sense of Place through Tactical Urbanism in Bundaran HI}

Although Lydon et al. (2015) revealed that action of tactical urbanism is often meant as a stunt to try to fix the design elements by criticizing city formal, in my opinion, it is not visible in the case studies. Tactical urbanism action, in this case, is purely conducted to fulfill the need for space of the actors without having someone who is ambitious to transform the area. Interventions on the Bundaran $\mathrm{HI}$ happens spontaneously in a specific time. In its intervention, the participation of citizens, livelihood, and quality of interaction is the main thing that contributes significantly to the tactical actions of urbanism, and critique towards this formal design is not the main base of the intervention.

Thus, the tactical urbanism is encouraged by the contribution of meanings and interpretations from the tactical urbanism actors in response to its environment increased the awareness of a place. In this case, the actors of tactical urbanism no longer become watchers who merely observe the environment, but their role changes to doers towards their environment. At Bundaran HI, visitors have become doers for the region, implied by their extended visits.

\section{CONCLUSION}

Tactical urbanism that occurs in the case study shows the characteristic of being opportunistic, with the basis of the needs of space to support community activities. The tactic itself is the use of a place that altered from its initial designated function of the place. Further action tactics are implied by the transformation of the roundabout's identity and function as a node into a place that has a whole other identity at night. On the other hand, the sense of place rate of this case is influenced by the intervention scope, area, as well as the actor's origin.

Opportunities were used by visitors and entrepreneurs, which is the food and beverage vendors. However, the primary initiator of the tactical urbanism movement was the visitors who eventually invited vendors as complementary actors. The complementary nature was given by vendors with the provision of their assets in the form of beverages, which lead to the enhancement of the interaction quality between the visitors and the length of time they have settled.

Based on the case studies conducted, the reflected character of tactical urbanism was the addition of elements to a place. However, the form of adding in the intervention was not distracted by the addition of physical elements. Instead, it involved the addition of masses of 
people. With regards to the act of tactical urbanism, the main character of tactical urbanism in Bundaran HI is the increase of crowds who brought the place alive by their spontaneous, bottom-up appearances.

The intervention has a background that consists of similar purposes of action and the type of activity, and that is as a form of recreation. Referring to this, the phenomenon of tactical urbanism that occurs in Bundaran HI is a type of optional activity in the outdoor space.

From this phenomenon, it can be seen that this adaptation of tactical urbanism is not intended to criticize formal urban design elements. The tactical urbanism was carried out to meet the background of the intervention, which is to purely fulfill the needs of recreation and business, without the main driving force whose ambition is to transform the built environment with longterm alteration of the city's physical features. Citizen participation, the spirit of the place, and the quality of interaction are the main things that contribute significantly to this adaptation of tactical urbanism, and criticism of formal urban planning is not the primary foundation of this intervention.

As the intervention progressed, the actor has become the part of social factors in building the sense of place. The emerge of actors is supported by the place's other spirit of place regarding physical factors. With Bundaran HI's scope as the symbol of Jakarta and its location that is in one of the busiest areas in Jakarta, visitors come from various places, which makes the visitors/actors' nature temporary and impermanent. Thus, their attachment to a place level is not reasonably strong.

Therefore, it can be concluded that tactical urbanism encourages the creation of a sense of place of an area through its actors' active role and interactions. The actors were able to interpret a place after having enough information about the image of the place, and thus their awareness was honed after which they can define the potential responses that will be conducted into the physical environment.

\section{ACKNOWLEDGEMENT}

This paper is a part of undergraduate thesis funded by PITTA (Publikasi Internasional Terindeks Untuk Tugas Akhir) Grant 2018. I also want to say thank you to the sources, the street coffee vendor and ten visitors of Bundaran HI that have provided information needed in the data collection.

\section{REFERENCES}

Beidler, K., Morrison, J., 2015. Sense of place: inquiry and application. Journal of Urbanism: International Research On Placemaking And Urban Sustainability, 9(3), 205-215.

Carmona, M., Heath, T., Oc, T., Tiesdell, S., 2003. Public Places, Urban Spaces. Oxford: Architectural Press

Gehl, J., 2011. Life between buildings. Washington, DC: Island Press.

Hou, J., 2010. (Not) Your Everyday Public Space. Insurgent Public Space: Guerrilla Urbanism and the Remaking of Contemporary Cities, edited by Jeffery Hou, 1-17. Oxford: Routledge.

Jackson, J. B., 1994. A sense of place, a sense of time. Yale University Press.

Lim, M., 2008. Transient Civic Spaces in Jakarta Demopolis. Globalization, the City and Civil Society in Pacific Asia: The Social Production of Civic Spaces, eds. Mike Douglass and Kong-Chong Ho, 211-230. New York, NY: Routledge.

Lydon, M., Garcia, A., Duany, A., 2015. Tactical Urbanism: Short Term Action for Long Term Change. Island Press.

Lynch, K., 1960. Image of The City. MIT Press. 
Najafi, M., Shariff, M. K. B. M., 2011. The concept of place and sense of place in architectural studies. International Journal of Human and Social Sciences, 6(3), 187-193.

Shamai, S., 1991. Sense of Place: An Empirical Measurement. Geoforum, 22(3), 347-358.

Silva, P., 2016. Tactical Urbanism: Towards an Evolutionary Cities' Approach?. Environment And Planning B: Planning And Design, 43(6), 1040-1051.

Spataro, D., 2015. Against a de-politicized DIY urbanism: Food Not Bombs and the struggle over public space. Journal of Urbanism: International Research on Placemaking And Urban Sustainability, 9(2), 185-201.

Steele, F., 1981. The Sense of Place. Boston: CBI Publishing Company.

Talen, E., 2015. Do-it-yourself urbanism: A history. Journal of Planning History, 14(2), 135148.

Tuan, Y., 1977. Space and Place: The Perspective of Experience. Minneapolis: University of Minnesota Press. 